\title{
NUMERICAL INVESTIGATIONS OF WAVED RIBS SHAPE'S INFLUENCE ON SPECIFIC STIFFNESS OF A PLATE.
}

\author{
Girts Frolovs ${ }^{1}$, Kārlis Rocēns ${ }^{2}$, Jānis Šliseris ${ }^{3}$ \\ ${ }^{1,2,3}$ Department of Structural Engineering, Faculty of Building and Civil Engineering, Riga Technical University, \\ Kalku st. 1, LV-1001 Riga, Latvia \\ E-mail:1 girts.frolovs@ rtu.lv (corresponding author); ${ }^{2}$ rocensk@latnet.lv; ${ }^{3}$ janis.sliseris@rtu.lv;
}

\begin{abstract}
This article shows numerical investigations of ribbed plywood panels with top and bottom plywood flanges and a core of curved plywood ribs. It is possible to vary with stiffness in transverse direction of a plate by changing form of panel ribs. This property can be described as structure's or material's level of anisotropy or the other results are describable as specific strength or stiffness (to mass of whole construction). The numerical simulation of plywood structure is done by using classical linear Kirchoff Love theory of thin plates and Finite Element Method. The various results depending on chosen variables (according to strength-stiffness criteria) plywood composite macrostructure is obtained for one span panel. Results show that by increasing number of waves it is possible to decrease level of anisotropy and by changing parameters of waves stiffness in transverse directions could be increased and these results can be used for creating ribbed panel design guidelines. It is proven that these parameters remain constant at different panel height. All FEM calculations were done by 3D ANSYS software.
\end{abstract}

Keywords: Plywood composite plates, structural optimization, numerical investigations, curved ribs.

\section{Introduction}

Minimal material consumption, structure weight, new rational structures and use of environmentally friendly materials in structures are the main directions of research in today's structural engineering science. Wood is one of the renewable natural resources and plywood sheets provide a rational use of it.

Traditionally used flat plywood sheets are not rational in many cases because of their slenderness and insufficient load bearing capacity. But the plates with waved vertically placed ribs show better results in mass to stiffness in transversal direction comparing to flat plates and also to ribbed panels with core consisting only of straight ribs. This ratio varies depending on curvature form (and height of a wave) and could be increased by successful optimizations of ribbed panel. The structure becomes more efficient if it's geometrical and mechanical parameters (technologically changeable) are optimized.

A significant material reduction could be reached by using sandwich structures instead of lamina in cases of thick flexural plates (Sliseris J., Rocens K., 2011) (Sliseris J., Rocēns K., 2010) (Sliseris J., Rocēns K., 2010) Sandwich plates could be modelled by using any of plates' theory in case if effective elastic properties of core are known. Effective elastic properties of sandwich could be obtained analytically or by using finite element method (Chen D.H., Yang L., 2011), (Manalo, A.C.; Aravinthan, T.; Karunasena, W.,, 2012).

A numerical simulations and experimental investigation (Manalo, A.C.; Aravinthan, T.; Karunasena, W.,, 2010) show that properties of core material and skins of flexural sandwich plates should not be uniform.

These plates could be used when there is important stiffness in both directions of a plate, for example in the structure of a roof or ceiling panelling and heavytruck floor, etc.

\section{Behaviour of panel with curved ribs}

Plywood panels with curved ribs (Fig. 1.) provide a lot of advantages- increased strength-to- mass ratio (Sliseris J., Rocēns K., 2010), (Sliseris J., Rocēns K., 2009), possibility to tailor material properties (Sliseris J., Rocēns K., 2012) for specific loading and boundary conditions. Curved plywood ribs could be manufacture by using unbalanced plywood sheets (Sliseris J., 2012). Sheets obtain curved shape while conditioning in special moisture temperature regime. The other way of producing waved ribs is to use already waved press when pressing ply sheets for plywood manufacturing, but this type provides constant form of curves without possibility to vary forms of curves.

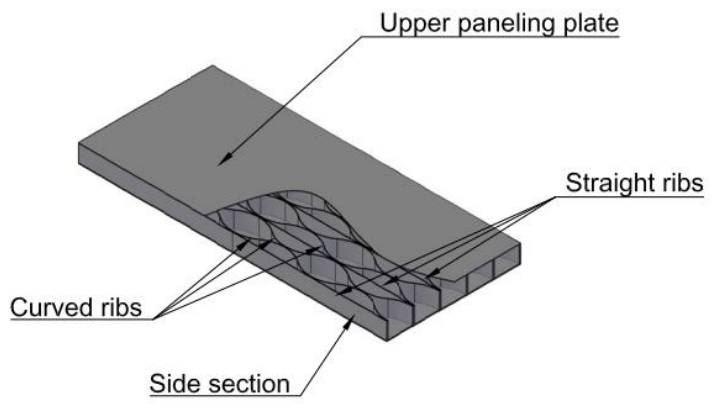

Fig. 1. Principal sketch of panel with curved and straight ribs

Wood materials are very sensitive to moisture variations that cause undesirable deformations (Sliseris J., Rocens K., 2011). Especially, if unbalanced composites are used. Moisture caused deformations should be reduced for plywood structures. An optimal thermal treatment procedure that minimizes moisture diffusion coefficient and moisture caused deformations is proposed in this paper.

The connections between straight ribs and waved ribs and these ribs' connections topanelling plates are obtained by a glued joint. 


\section{Material properties}

A birch plywood sheets were chosen for all parts of plate(panelling, straight ribs and curved ribs). Material properties applied for birch plywood Mechanical properties of plywood sheet (Pereligin L.M., Ugolev B.N., 1971) are summarized in Table 1.

Table 1. Mechanical properties of a single ply sheet

\begin{tabular}{|c|c|c|c|}
\hline Name of the elastic property & Symbol & Value & Unit \\
\hline $\begin{array}{l}\text { Modulus of elasticity in } \\
\text { longitudinal direction }\end{array}$ & $E_{x}$ & 16.4 & GPa \\
\hline $\begin{array}{l}\text { Modulus of elasticity in } \\
\text { tangential direction }\end{array}$ & $\mathrm{Ey}_{\mathrm{y}}$ & 0.68 & GPa \\
\hline $\begin{array}{l}\text { Modulus of elasticity radial } \\
\text { direction }\end{array}$ & $\mathrm{E}_{\mathrm{z}}$ & 0.53 & GPa \\
\hline $\begin{array}{l}\text { Poisson ratio in fibre } \\
\text { direction }\end{array}$ & $P_{x y}$ & 0.04 & \\
\hline $\begin{array}{l}\text { Poisson ratio perpendicular } \\
\text { to fibre direction }\end{array}$ & $\mathrm{P}_{\mathrm{yz}}$ & 0.81 & \\
\hline $\begin{array}{l}\text { Poisson ratio perpendicular } \\
\text { to fibre direction }\end{array}$ & $\mathrm{P}_{\mathrm{xz}}$ & 0.42 & \\
\hline Shear modulus in xy plane & $\mathrm{G}_{\mathrm{xy}}$ & 0.89 & GPa \\
\hline Shear modulus in yz plane & $\mathrm{G}_{\mathrm{xz}}$ & 0.23 & GPa \\
\hline Shear modulus in xz plane & $\mathrm{G}_{\mathrm{yz}}$ & 1.54 & GPa \\
\hline Density & $\rho$ & 650 & $\mathrm{~kg} / \mathrm{m}^{3}$ \\
\hline
\end{tabular}

Plywood stacking sequence has been modelled assuming that each layer is perpendicular to the upper and lower one, as plywood consists of an odd number of plies. In this paper there was three layer plywood used.

\section{Optimization methodology}

The optimization results are shown for one typical part of a plate's width which can be multiplied several times to get whole plate. In these example 4 straight ribs with waved ribs from both sides and edge elements with waved ribs just from one side. For all waved ribs there are 4 waves (with width of L1 see in Fig. 2.a).

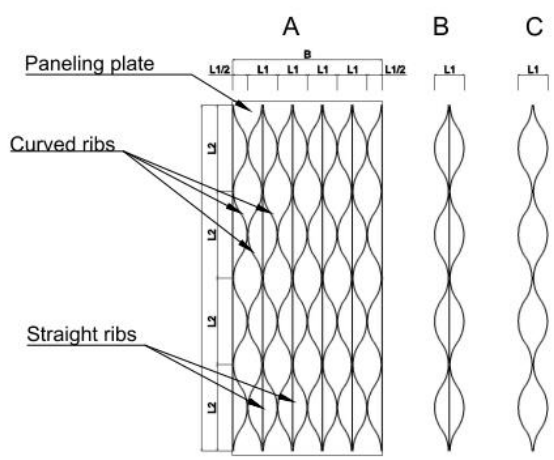

Fig. 2. Panel sketches with straight and waved ribs. ( $\mathrm{a}$ - whole panel; b - part of a panel type with straight and waved ribs; $\mathrm{c}-$ part of a panel type with waved ribs)

The two types of ribs can be used - straight ribs and curved ribs from both sides and the type with only curved ribs without straight rib in the middle of this part.

For numerical simulation of the bending tests a FEM commercial code ANSYS v.13 (2010) has been applied. A parametrical model of the panel was created with variable cross section parameters and bending loading set up options (according to Eurocode 5). The finite element mesh size is chosen $1 / 5$ of a panel height. All plates (upper, lower and waved core plates) are defined by using ANSYS 4-node shell element SHELL 181. Three layers plywood was taken for all parts of a plate with total thickness of one plywood sheet of $3.8 \mathrm{~mm}$. It has been assumed that each ply has same thickness of $1.27 \mathrm{~mm}$ and transversal isotropic material properties (see Table 1.)

In each step there was new numerical model made and calculated and changed supports in first step span at longitude direction and as next in transverse direction

All plates were loaded with uniformly distributed load with intensity of $1 \mathrm{kN} / \mathrm{m}^{2}$

Biggest specific strength is achieved by keeping constant thickness skins and modifying only geometry of ribs to obtain necessary stiffness (Sliseris J., Rocēns K., 2012).

Table 2. Design variables

\begin{tabular}{l|c|c|c|c|c}
\hline Parameter & Symbol & $\begin{array}{c}\text { Lower } \\
\text { limit }\end{array}$ & $\begin{array}{c}\text { Upper } \\
\text { limit }\end{array}$ & $\begin{array}{c}\text { Increment } \\
\text { steps }\end{array}$ & Units \\
\hline $\begin{array}{l}\text { Heigth of a } \\
\text { panel }\end{array}$ & $\mathrm{H}$ & 0.01 & 0.05 & 0.01 & $\mathrm{~m}$ \\
$\begin{array}{l}\text { Length of a } \\
\text { panel }\end{array}$ & $\mathrm{L}$ & 1.0 & 2.5 & 0.5 & $\mathrm{~m}$ \\
$\begin{array}{l}\text { Height of } \\
\text { waves } \\
\text { (L1=B/N1) }\end{array}$ & $\mathrm{L} 1$ & $\mathrm{~L} / 25$ & $\mathrm{~L} / 5$ & $\mathrm{~L} / 25$ & $\mathrm{~m}$ \\
$\begin{array}{l}\text { Length of } \\
\text { waves } \\
\text { (L2=L/N2) }\end{array}$ & $\mathrm{N} 2$ & 0 & 8 & 1 & \\
\hline
\end{tabular}




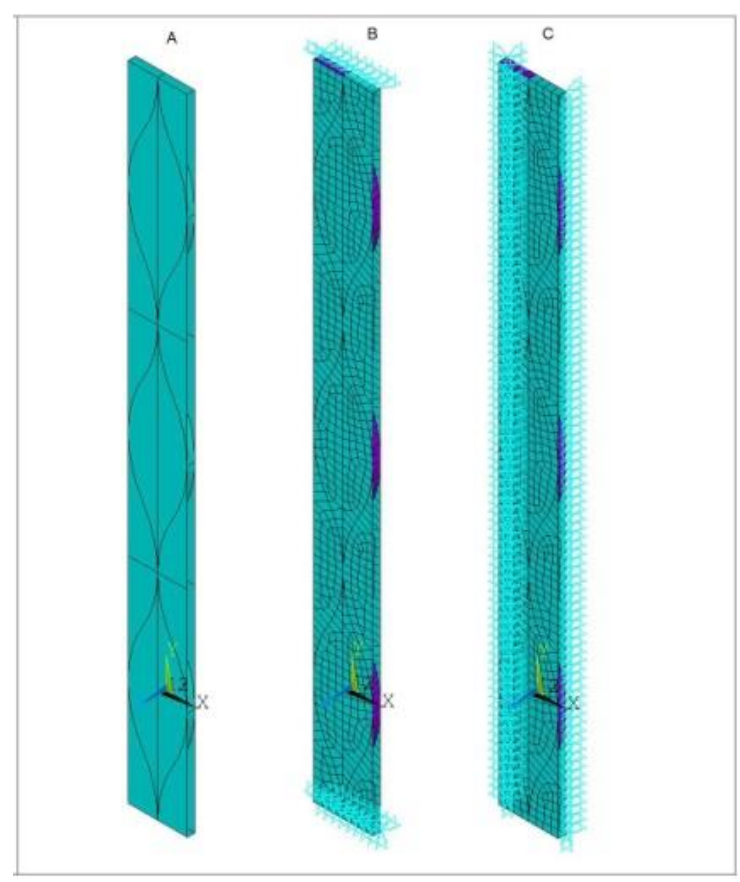

Fig. 3. FEM model sketch with straight and waved ribs (A - designed areas; B - meshed areas with supports in longitude directions; C - meshed areas with supports in transversal directions)

The chosen principal FEM model are shown in Fig. 4. Supports are designed as freely supported plate.

To describe characteristics of anisotropy it is easier to use ratio of bending stiffness in main direction, which can be calculated by:

$$
A=\frac{(E I)_{1}}{(E I)_{2}}
$$

where: $E I_{1}$ - plate's bending stiffness in longitudinal direction, $E I_{2^{-}}$plate's bending stiffness in transverse direction

\section{Obtained results}

For all plates' height values a separate plot has been shown (Fig. 5-Fig. 6) as well as for plate with just waved ribs for Fig. 22.c seen in Fig. 7.

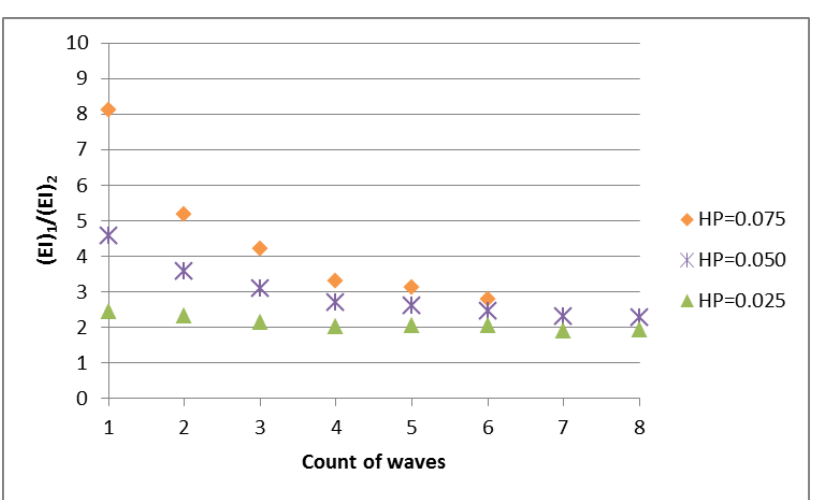

Fig. 5. Characteristics of anisotropy depending on a number of waves for plate with straight and curved ribs

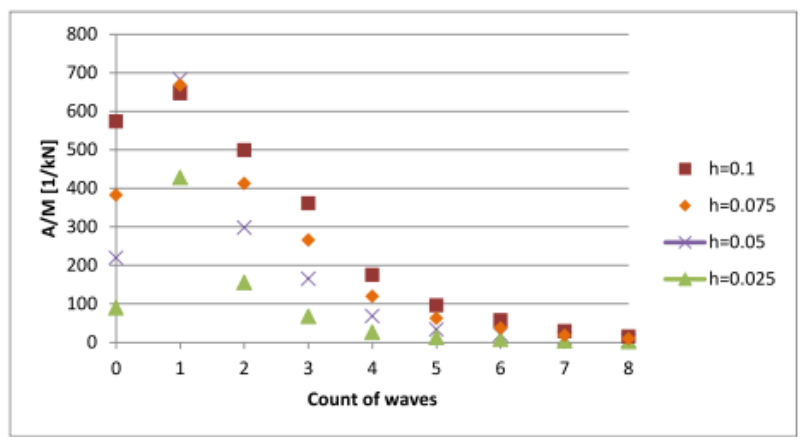

Fig. 6. Characteristics of anisotropy to mass ratio depending on a number of waves for plate with only curved ribs

It is noticeable that the ratio of stiffnesses decreases exponentially by increment of the number of waves per span.

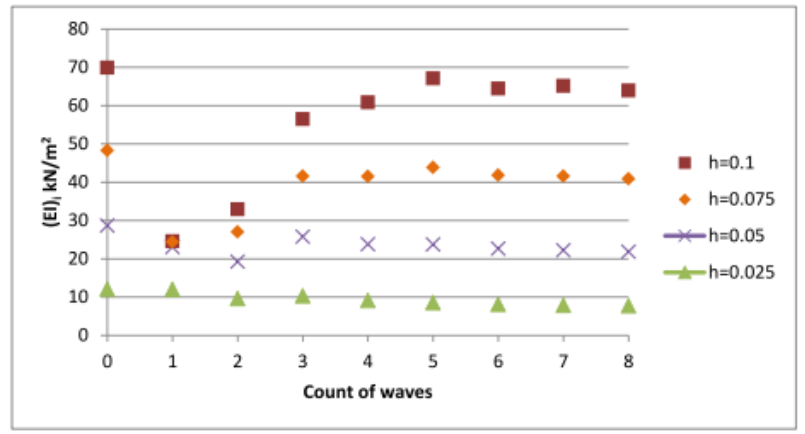

Fig. 7. Longitude stiffness depending on a number of waves

Stiffness in longitudinal direction changes insignificant because there is more material consumption on ribs. The is significant increase of stiffness in transversal direction of a plate when number of waves increases (Fig. 8).

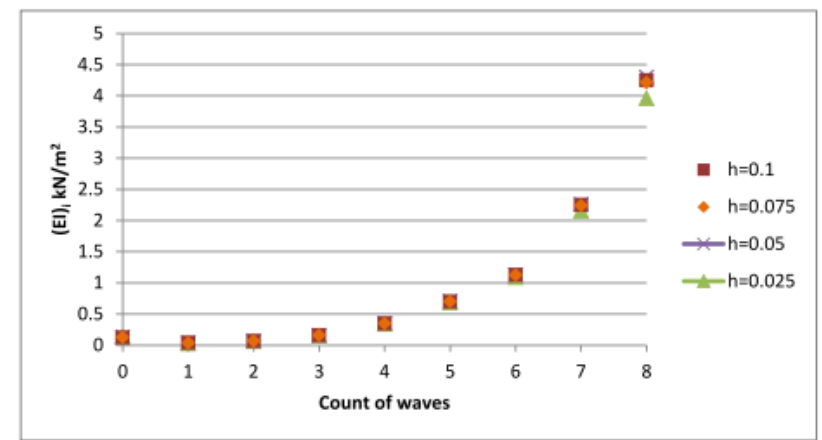

Fig. 8. Transversal stiffness depending on a number of waves

The stresses in longitudinal direction of plywood sheets increases but in transversal direction decreases by increasing number of waves.

The similar results could be achieved by making plate without flat ribs (see fig. 2.c) by increasing number of waves. The ratio of stifnesses decreases when the number of weaves increases (Fig. 8). 


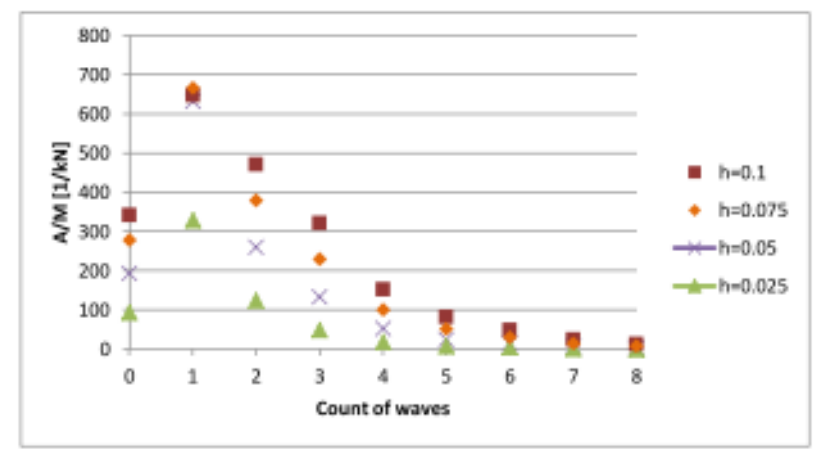

Fig. 9. Level of anisotropy to mass ratio depending on a number of waves for plate with only curved ribs

The ratio of stiffnesses decreases by increasing number of waves. It is seen that ratio of stiffnesses differs by increasing plate height (Fig. 10) and also when increase height of a waves (L1 in Fig. 22). Ratio of stiffnesses decreases when number of waves increases (Fig. 11).

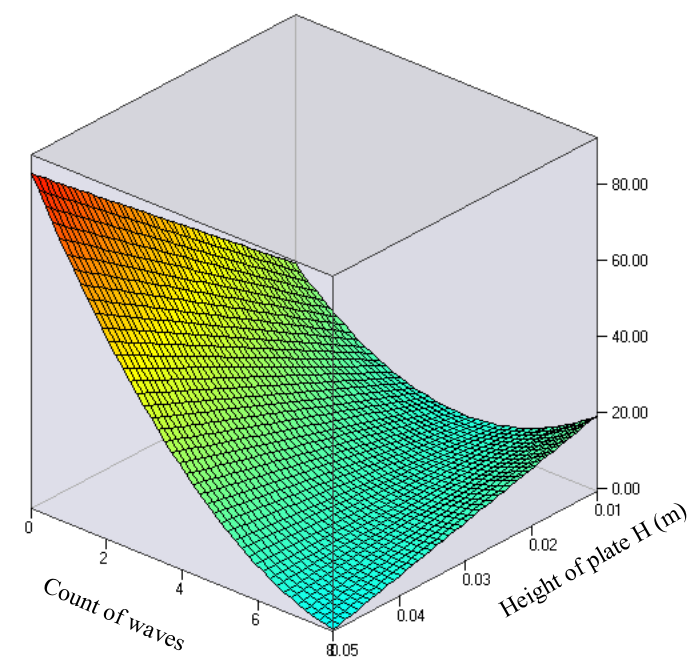

Fig. 10. Anisotropy depending on a number of waves and plate height

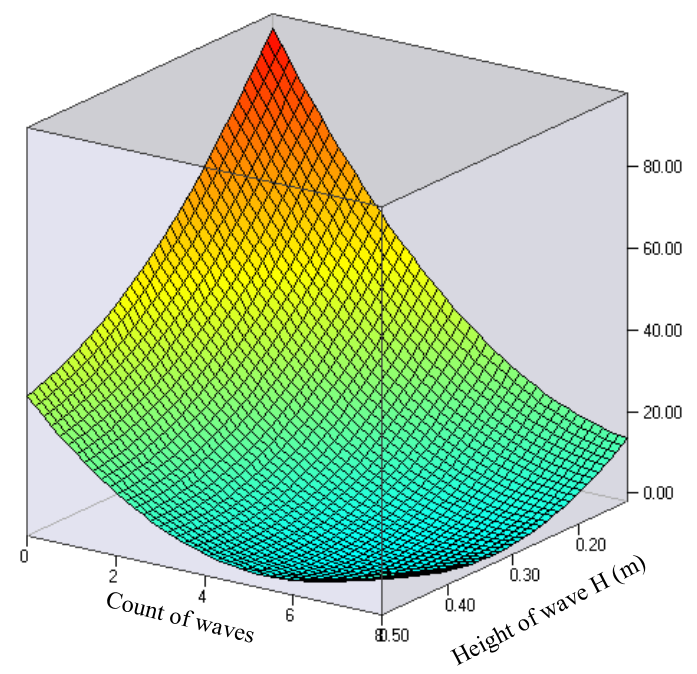

Fig. 11. Anisotropy depending on a number of waves and wave height
The achieved anisotropy depending on wave height is showed for each panel thickness in Fig. 11. It is shown that that plate stiffness in transversal direction is largely dependent on the height of waves. For more waves the ratio of stiffnesses decreases. Ratio of stiffnesses decreases by increasing plates height. Ratio of stiffnesses decreases less significant when increasing plates height than number of waves.

\section{Plates model analysis}

One typical part of the whole plate was optimized and analysed according to results from the previous analysis the whole plate. The plate with length $2.5 \mathrm{~m}$ and width $1.2 \mathrm{~m}$ was analysed. It consists of middle part elements and side elements from both sides as described before (see Fig. 22.a). The RM ratio of value 1.8 was achieved by optimization and the optimal design (calculated value 1.78 ) is $0.3 \mathrm{~m}$ high 7 waves (e.g. height of a panel, maximum number and length of waves as in Table 2.).

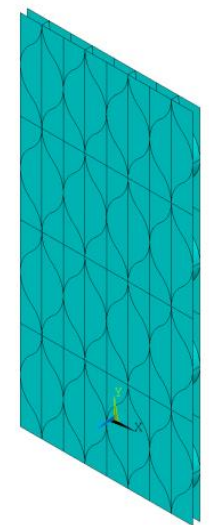

Fig. 12. The structure of optimal plate for RM ratio 1.8 (1.78)

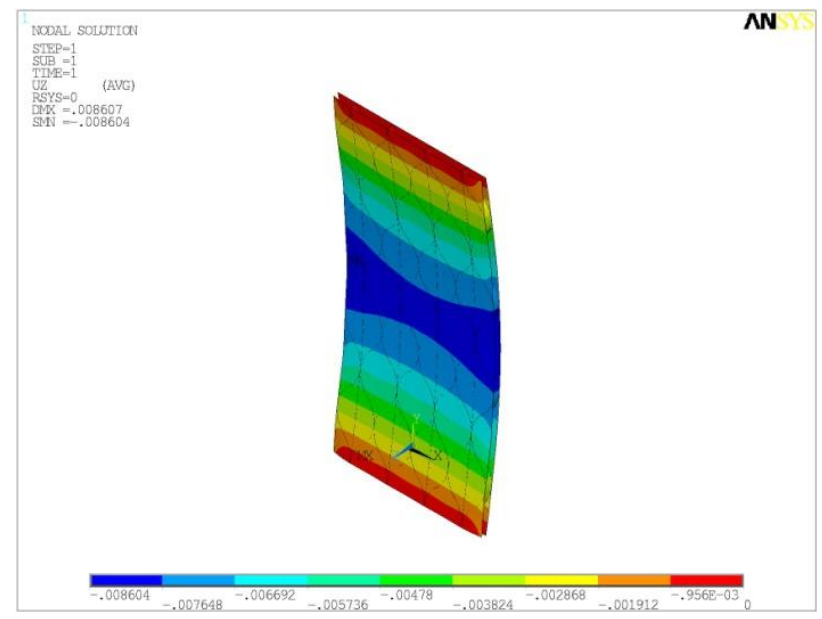

Fig. 13. Deflection of plate with span in longitudinal direction (for plate with ratio of stiffnesses 1.8) 


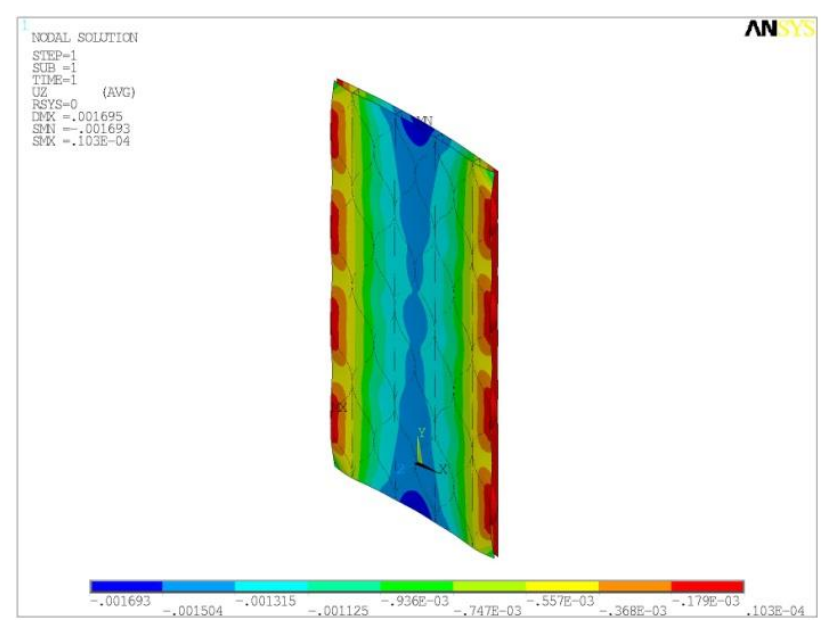

Fig. 14. Deflection of plate with span in longitudinal direction (for plate withratio of stiffnesses 1.8)

\section{Conclusions}

The influence the shape of ribs on rational geometrical properties of the proposed structure is obtained.

According to obtained results it is possible to choose optimal ribbed structure with necessary ratio of anisotropy.

A method that allows to place needed insulation between ribs should be studied in the future. Technological principles of forming and fixing waved ribs should be detailed analysed.

\section{References}

Chen D. H., Yang L. (2011). Analysis of equivalent elastic modulus of asymmetrical honeycomb. Composite Structures 93, p. 767-773.

http://dx.doi.org/10.1016/j.compstruct.2010.07.014

Eurocode 5: Design of timber structures - Part 1-1: Generalcommon rules and rules for buildings. (n.d.).

Manalo, A. C.; Aravinthan, T.; Karunasena, W.,. (2010). Flexural behaviour of glue-laminated fibre composite sandwich beams. Composite Structures 92, 2703-2711. http://dx.doi.org/10.1016/j.compstruct.2010.03.006

Manalo, A. C.; Aravinthan, T.; Karunasena, W.,. (2012). Flexural analysis of discontinous tile core sandwich structure. Composite Structures 94, 1524-1532. http://dx.doi.org/10.1016/j.compstruct.2011.11.028

Pereligin L. M., Ugolev B. N. (1971). Wood Science (In Russian). Moskau, Russia: Lesnaja promislennostj.

Sliseris J., R. K. (2012). Patent No. P-12-52. Riga: Latvijas patentu valde.

Sliseris J., Rocens K. (2011). Non-uniform moisture influence on multilayer corrugated plywood shell. (pp. 723-730). Tampere: "Proceedings of 9th Nordic Symposium on Building Physics- NSB".

Sliseris J., Rocēns K. (2009). Curvature analysis for asymmetrical multi-layer composite. Construction Science, p. 139-146.

Sliseris J., Rocēns K. (2010). Behaviour of multilayer sheets with technological imperfection. Proceedings of 10th International conference Modern Building Materials, Structures and Techniques", (pp.793-798). Vilnius, Lithuania.

Sliseris J., Rocēns K. (2010). Curvature analysis for composite with orthogonal, asymmetrical multi layer structure. Journal of Civil Engineering and Management, p. 242-248. http://dx.doi.org/10.3846/jcem.2010.28

Sliseris J., Rocēns K. (2012). Optimization of multispan ribbed plywood plate macro-structure for multiple load cases. Journal of Civil Engineering and management (Accepted to publish). 